\title{
ЧЕЛОВЕК. ЖИЗНЬ. ОТВЕТСТВЕННОСТЬ (ДИАЛОГ Г. ЙОНАСА, Э. МАЙРА И С. ДОННЕЛЛИ)
}

\section{HUMAN. LIFE. RESPONSIBILITY (DIALOGUE OF H. JONAS, E. MAYRA AND S. DONNELLI)}

\section{N. Pugacheva}

Summary: The article is devoted to the analysis of the category of life in ontological axiology of the philosopher Hans Jonas in comparison with the evolutionary theory of the biologist Ernst Mayr. The development of organic and moral freedom in the history of life and the organism is shown. The relationship of biology and ethics is analyzed. The concept of $\mathrm{H}$. Jonas is presented as an ontological revolution in philosophy, which led to the establishment of the ethics of life.

Keywords: H. Jonas, E. Mayr, S. Donnelly, life, organism, freedom, responsibility.
Пугачева Наталья Петровна

К.ф.н., дочент, Пензенский государственный аграрный университет

kozlova_natalya@list.ru

Аннотация: Статья посвящена анализу категории жизни в онтологической аксиологии немецко-американского философа Ганса Йонаса в сравнении с эволюционной теорией биолога Эрнста Майра. Показывается развитие органической и моральной свободы в истории жизни и организма. Анализируется связь биологии и этики. Концепция Г. Йонаса представляется как онтологическая революция в философии, приведшая к становлению этики жизни.

Ключевые слова: Г. Йонас, Э. Майр, С. Доннелли, жизнь, организм, свобода, ответственность.
$\mathrm{B}$ современной научной картине мира жизнь перестает быть чисто биологической категорий, претендуя стать тем самым «мостом», соединяющим естественнонаучное и социально-гуманитарное знание. В качестве живого примера можно привести творчество философствующего биолога Эрнста Майра (1904-2005) и философа, занимавшегося проблемой жизни и организма, Ганса Йонаса (1903-1993). Оба они стали свидетелями глобальных изменений в социуме и науке, прожившими практически весь «костоломный» XX век. И тот, и другой - выходцы из Германии, по разным причинам покинувшие ее и нашедшие последний приют в США. Майр и Йонас стояли у истоков философии биологии и являются авторами революций: Майр - в эволюционной биологии, Йонас - в философии живого [2].

Майра считают одним из авторов синтетической теории эволюции и новой концепции биологического вида. Он отвергал редукционизм, считая, что эволюция захватывает весь организм, а не отдельные гены; отрицал идею личного Бога, полагая, что нет ничего, поддерживающего его; критиковал поиск внеземного разума и был ярым защитником научного метода; резко выступал против различных евгенических проектов, указывая на сложный характер наследования духовных и этических качеств и генетическую уникальность каждого человека [1].

В обращении главного редактора журнала «Природа» А.К. Скворцова, посвященном столетию ученого, в качестве одной из проблем, поставленных Майром, значится специфичность биологии, ее отличие от наук фи- зического цикла, поскольку среди живых объектов нет двух идентичных, они все уникальные [3; С. 70]. Поэтому в биологии изначально имеется связь с этикой, в отличие от физики.

Ганс Йонас в своих главных работах «Организм и свобода» (1973) и «Принцип ответственности. Опыт этики для технологической цивилизации» (1979), а также в многочисленных эссе обращает наше внимание на онтологическую уникальность живого организма, необходимость перестройки традиционной этики вокруг принципа ответственности за будущее. Он пытается уйти от редукционизма и дуализма и в своей философии биологии, в отличие от Майра, сосредотачивается не на эволюции (становлении и развитии) жизни, а на бытии организма, содержащего потенцию свободы и моральности.

По сути, философия биология в творчестве Йонаса становится этикой жизни - это одна из основных идей коллективной монографии «Человек. Бог. Мир. Философия жизни, религиозная философия и метафизика в творчестве Ганса Йонаса». Этот сборник стал ярким итогом многолетней работы последователей и верных учеников мыслителя [8]. Одним из наиболее репрезентативных разделов книги является очерк С. Доннелли (Strachan Donnelly) «Ганс Йонас и Эрнст Майр: об органической жизни и человеческой ответственности» [5].

Страхан Доннелли (1942-2008) - доктор философии, основатель (2003) и президент Центра человека и природы (The Center for Humans and Nature, Иллинойс). До 
его создания был президентом (1996-1999) Гастингс-центра (Hastings Center), института биоэтики, и директором его программы «Люди и природа», руководил рядом исследовательских проектов в области окружающей среды («Этика опытов над животными», «Биотехнология животных и природа» и др.).

Доннелли редактировал специальное издание Центра (1995) о Гансе Йонасе, подчеркнув значимость его философии организма: «Такая интеллектуальная осмотрительность или скромность дает Йонасу умозрительную философскую возможность вернуться к повседневному опыту, выйти (как Уайтхед) за пределы унаследованных гун материализма и идеализма и систематически исследовать «цель природы», которая проявляется во всей органической, эволюционной жизни, в том числе животных и людей... Все подлинные примеры органической (особенно животной) жизни пользуются той или иной формой самочувствия, самости, «нуждающейся свободы» и активного обмена с миром» [4; Р. 28].

Доннелли - автор многочисленных статей по философии, эволюционной биологии и этической ответственности. Его докторская диссертация была посвящена философии Альфреда Норта Уайтхеда «Живое тело: организмы и ценность». С раннего детства страстно влюбленный в реки и земли Иллинойса Доннелли назвал себя самопровозглашенным «философом ловли рыбы нахлыстом», который осознал острую необходимость в создании организации, занимающейся изучением взаимоотношений человека и природы. Убежденный в пагубности редукционизма он призывал к диалогу биологов, экологов, экономистов, инженеров, поэтов, художников, философов со всего мира, чтобы открыть глаза на долгосрочные последствия жизни людей на этой планете. Доннелли писал живым неповторимым языком: «Даже для того, чтобы начать обсуждение этики экспериментов над животными, мы должны найти свое место в "этическом цирке с тремя кольцами" - дебатах между "людьми-борцами за права человека", "права животных" и теми, кто находится в "проблемной середине"» [6; Р. 16].

Названная нами работа о Гансе Йонасе и Эрнсте Майре вышла в сборнике «Человек. Бог. Мир» как раз в год смерти «философа ловли рыбы нахлыстом». Посмертно была опубликована его книга «Философия пруда-лягушки» (2018), содержащая яркие очерки, основанные на личном опыте и отражающие взгляд на актуальные проблемы современности.

В данной статье представлен краткий обзор очерка С. Доннелли «Ганс Йонас и Эрнст Майр: об органической жизни и человеческой ответственности».

Во время коллоквиума «Возвращаясь к природе: наследие Чарльза Дарвина и Олдо Леопольда» («Revisiting
Nature: the Legacies of Charles Darwin and Aldo Leopold», 1996) в рамках исследовательского проекта «Люди и природа», организуемого Гастингс-центром, Эрнст Майр сказал о Гансе Йонасе: «Он был одним из немногих мыслителей, которые всерьез принимали органическую жизнь и организмы. Он был неправ, но он был философски и морально серьезен» [5; S. 41]. Доннели обращает внимание на то, что начиная с этого коллоквиума и теперь в «Центре человека и природы» делаются попытки связать в идее долгосрочной и взаимопроникающей ответственности человеческие сообщества, естественные экосистемы и ландшафты. Вызов, давно брошенный Йонасом и Майром, становится явственной моральной и общегражданской проблемой нашего времени. Проблемы, касающиеся системы «человек-природа», навязываются со всех сторон: экологически «непереносимые» города и сельскохозяйственные практики, антибиотики в здоровой системе, глобальное крушение морского рыболовства, другие формы жизни и т.д. - буквально «так называемое событие вымирания человека». И все эти проблемы являются не только практическими, моральными и социальными - они требуют теоретических и концептуальных обоснований. Необходимо исследовать взаимовлияние философии, эволюционной биологии и этики, и в аспекте встречи людей с природой в повседневной жизни. Сравнивая, Эрнста Майра, эволюционного биолога и философа биологии, и Ганса Йонаса, этика и философа органической жизни, можно рассмотреть главную проблему нашей практической ответственности по отношению к человеку м миру природы, справедливо считает Доннелли.

Природа Майра - динамическое гераклитовское царство, содержащее в качестве центрального элемента ДНК, ген и геном - материал, незнакомый ньютоновскому физикализму. Специфические исторические измерения и процессы выходят за рамки физических и химических знаний, то есть биология как наука «трансцендирует» физику и химию. Наличие генетической программы меняет представление о причинности. Индивидуальный организм - «фенотип» - с которым мы встречаемся в нашем повседневном опыте - нечто «возникшее или постоянно возникающее» до тех пор, пока он не умрет. Это взаимоотношение генома, клеточной и соматической телесности и экосистематической «окрестности» тела - индивидуальный «интерактер» в генерации будущего мира. Концепция возникновения поднимает философский вопрос о природе индивидуального организма, включая человеческого индивидуума или самость - это одна из любимых тем Ганса Йонаса.

Если Майр производит революцию в эволюционном учении, то Йонас претендует на революцию в философии. В работе «Организм и свобода», «Философских эссе», «Принципе ответственности» Йонас подвергает критике онтологический дуализм духа и материи, не 
оставивший места для адекватной философской интерпретации органической индивидуальности, идентичности и телесной жизненности - человеческой или нечеловеческой [7; S. 32-39].

Йонас возвращается к повседневному человеческому опыту и делает упор на субъективности, индивидуальном действии и целеустремленности. Он принимает дарвиновское учение. Если мы непосредственно или косвенно связаны со всеми формами жизни на земле, то субъективность, индивидуальность и целеустремленность, находимую в нас самих, мы можем находить и в органически-биологическом другом, в других видах и организмах, пусть даже и в рудиментарном виде. В этом смысл метода отката «назад» - от человеческого примера во всю область органического бытия. Таковы философские, феноменологические и спекулятивные интерпретации органического, по Йонасу, считает Доннелли.

Метаболический образ существования организмов говорит о свободе от мира, которая состоит в еще большей зависимости от естественного, материального, мира. «Организмы наслаждаются онтологическим статусом, обозначаемым им как нуждающаяся свобода» [5; S. 54]. Организм, его идентичность определяются через понятие живой формы, которая существует через и над ее прошлыми материальными составными частями. Образ жизни организма требует активного действия живая форма воплощает активное «нет небытию», безжизненности и бесценности неорганической природы. Йонас считает органическую жизнь онтологической революцией в истории материи, радикальным способом изменения ее бытия. Жизнь привносит в мир ценность в виде целевого существования, в чем состоит онтологическое и космологическое начало «нуждающейся свободы», проявляющейся в метаболическом существовании.

Йонас делает наброски различных измерений нуждающейся свободы от одноклеточного организма через растительное существование к животному бытию и, наконец, человеческой экзистенции во всех ее проявлениях - от экономических и социальных, через политические, научные и технологические, к эстетическим, этическим и духовным. В ходе эволюции возникают новые способности, свидетельствующие о новой ступени свободы, новой форме независимости от мира: движение, ощущение, чувствительность, восприятие смысла, практический и теоретический разум. Жизненная форма всех организмов, телесная самость человека открывают онтологическую, экзистенциальную структуру нуждающейся свободы. Организмы, ценность их жизни - смертной, уязвимой - философски подводят к идее их права. Благодаря ценности, смыслу и значению оживленная природа философски реабилитируется и человек «натурализируется», подвергается переосмыслению.
В отличие от Майра, Йонас относительно мало интересуется конкретной историей природы: эволюционной и экологической. Он больше обращается к экзистенциальной драме, внутренней жизни, мировому приключению, включая моральную ответственность человека. «Нуждающиеся свободы - и нуждающиеся ответственности - доминирующие темы его философских изысканий» [5; S. 56]. В этом и неповторимая сила и слабость философии, или, по меньшей мере, этики Йонаса. Сила ее - в феноменологическом раскрытии органической жизни, включая человеческую: что это значит - быть организмом и чувствовать себя им. С другой стороны, учитывая эволюционную историю, философ не в полной мере использует размах и великолепие естественно-исторической драмы, когда образы жизни возникают динамично и взаимосвязано (популяционно и экосистематически) на фоне постоянного отбора и биотических вариаций. «Эта абсолютно аморальная история земли попросту очаровывает и восхищает философствующего биолога Майра. Тем не менее, она не возбуждает внимания и воображения философа организма Ганса Йонаса» [5; S. 56]. По мнению Доннелли, Йонас недооценил роль симбиотических и противоречивых аспектов предчеловеческой, человеческой, экосистематической жизни для этики.

Йонас - философ, моральный экзистенциалист, обладающий внимательным этическим и духовным взором, способным увидеть как нравственно предосудительное и отвратительное, так и похвальное и благородное. Этот взор укреплялся до, во время и после гитлеровской оккупации и Второй мировой войны. По натуре христианин отрекался и Майр от своей родины Германии по «причинам совести» (он находился за пределами Европы, занимаясь биологическими полевыми исследованиями), но был не так абсолютен, как Йонас, давший себе клятву не возвращаться в Германию никак иначе, кроме как солдат победоносной армии освобождения. В котлованах Второй мировой Йонас впервые почувствовал интерес к философии жизни и организма - интерес, который с самого начала имел моральный импульс. Это наблюдение Доннелли свидетельствует о глубоком прочувствовании не только творчества Йонаса, но и трагедии его личной судьбы.

Очевиднее всего различия во взглядах Йонаса и Майра прослеживаются в вопросах морали и этической ответственности. В обоих случаях имеется в виду, прежде всего ответственность за человечество, которая подразумевает ответственность за природу. «Однако оба достигают этого морального Рима абсолютно разным этическим путем» [5; S. 58].

Майр находит корни нашей моральной жизни в эволюционных процессах, когда речь идет о социальных группировках животных и больших сообществах, «вза- 
имном альтруизме». Люди, благодаря своему, отточенному во времени на опыте, генетическому «оборудованию» могут учиться, принимать участие в человеческой культуре и ее креативно развивать, решать самостоятельно вещи для нас, свободно и ответственно, в пределах ограничений (в том числе, генетических) и возможностей мира. Будущее открыто, неопределенно, принципиально не предсказуемо и мы своими действиями все больше склоняем его к плохому сценарию. Плюрализм человеческих общностей, и моральный, вполне согласуется с популяционным мышлением Майра. Недостаток биологических знаний - вполне серьезный вопрос, если мы хотим и в будущем развиваться именно «человечно». Майр присоединяется к О. Леопольду и другим экозащитникам и натуралистам в требовании ответственности за благополучие природы, за защиту продолжающихся эволюционных, экологических, культурных процессов.

Так же и Йонас требует выполнение долга по отношению к будущему человека и природы. Это «сердце» его книги «Принцип ответственности». Он возводит человеческую моральность и ответственность к естественным, органическим истокам - в частности, к родительскому чувству по отношению к ребенку - естественному чувству и ответственности за в высшей степени уязвимое и нуждающееся существо. Фундаментальная ценность всей жизни и всех органических существ коренится в той самой онтологической революции - способности сказать «нет небытию», активному утверждению самости в мире, опасном смертью, в виде каждого индивида, вида и всей жизни. Если возможность жизни включает возможность моральной ответственности, как это происходит в случае человечества, мы достигаем «абсолютно моральной пограничной области и ультимативного категорического императива, как онтологического, так и морального: человечество и так необходимая для человечества природа, как и морально ответственная жизнь, “должны быть"» [5; S. 59]. В отношении этого категорического императива мы не можем выбрать свободу действовать безответственно. Моральная ответственность, которую люди несут в себе потенциально, как и сам человек - последняя цель, по Йонасу. Безусловно кантианский оттенок в виде трансцендентальной абсолютности сохраняется в моральной аргументации философа.

Новые философские космологии Майра и Йонаса, способствующие пониманию органической жизни, по существу «интеракционистские». У обоих мыслителей налицо взаимодействие (интеракция) индивидуального философского мировоззрения, научных концепций, этических убеждений и личных отношений с человеческим и природным миром.

Наш опыт, включая философское, научное и этическое образование и рефлексию, без сомнения, втекает в наше настоящее Я, из которого вырастает наше персо- нальное будущее в мире. Это первоначальные встречи и взаимоотношения с миром, в которых мы получаем этические обязательства и отвечаем потом на них в зависимости от того, как мы были «проинформированы» предшествующим интеллектуальным и культурным «приключением». Опыт этического долженствования или обязательства, подготовленной естественной и культурной эволюцией, является жизненно важной «организмической реакцией» на мир, которая характеризуется моральной окраской (чувством долженствования). «Это всемирный горизонт человеческой свободы и ответственности» [5; S. 62].

Неистощимое богатство и сложность мира, которые познаются человеком, не могут быть охвачены философией, наукой и этикой. Майр как философ - скорее борец за естественное и человеческое становление - от природных и культурных процессов, систем и форм во все многообразие мира. И это человеческое и природное «шоу» развивается беспрерывно. Йонас как философ борец за органическое и человеческое бытие. Он меньше обращает внимание на бесчисленные материальные формы и процессы жизни, сосредоточиваясь на факте самой жизни, особенно способности органической жизни к моральной ответственности, развивающейся в человеке. То, что в огромной вселенной, представленной в основном мертвой неорганической материей, возникли живые и моральные существа как «бунт против смерти и бесполезности» [5; S. 64] - удивительный факт, который мы должны сохранить.

В случае Майра и Йонаса разным способом сложились взаимоотношения философии, биологии, этики и личного опыта. В произведении «Принцип ответственности» Йонас, «участник войн XX столетия и свидетель его зверств, смотрит в лицо современной жизни и нашим акселерированным технологиям» [5; S. 64]. В центре этической ответственности должна находиться долгосрочная перспектива будущего человека и природы. И это должно гарантироваться метафизическим и философским обоснованием. В свою философию и этику Йонас берет из эволюционной биологии то, что ему необходимо. А Майр, как натуралист, использует нужные ему философские концепции, соответствующим образом характеризуя моральную жизнь биологически, с точки зрения исторической эволюции природы и человека. Акценты философа организма Йонаса и философствующего биолога Майра, таким образом, различны.

Доннелли снова вспоминает экологические проблемы современности, особенно «монокультивирование» (сокращение генетического разнообразия) живого мира, не говоря о клонировании человека. Эти реалии требуют ответственности, простирающейся на природу, возлагаемой на нас историческим положением дел, не требующей никакой логической дедукции для ее призна- 
ния. Хорошо, что есть Йонас и Майр, замечает Доннелли, с их различным видением нашей ответственности. Не можем же мы отдать формы живой жизни, включая нашу собственную, «мраку ничто»... «Чтобы воплотить ответственность, распространяющуюся на природу - нашу ответственность по отношению к природе вещей, данности “человека и природы" в мире - это счастье, что у нас есть Майр и Йонас и другие философы и этики» [5; S. 66].

Йонас понимает органическую жизнь как беспрецедентную онтологическую эволюцию в истории материи. Происхождение жизни лежит по ту сторону нашего философского познания. Но однажды возникнув, жизнь существует в своей радикальной полноте и противопоставлении мертвой неорганической природе. Целесообразность, целенаправленность, дееспособность субъекта, забота о себе и самоценность, а затем моральность и человеческая ответственность - все это создает непроходимую «онтологическую пропасть» с неорганическим миром. Это несколько напоминает картезианский дуализм духа и материи, (с которым сам Йонас пытался бороться - Н.П.). Тем не менее, жизнь в силу необходимости материальна. И как только она выходит на онтоло- гическую сцену, можно говорить об эволюции, развитии бытия к цели и «нуждающейся свободе» - это имманентно естественный, исторический и в некоторой степени культурный процесс. «На конференции в Иерусалиме в начале 90-х годов, незадолго до его (Йонаса) смерти, я спрашивал его, является ли полная самоотдача Бога миру - еще более радикальный акт, чем пожертвование сына на благо человечества через христианского Бога - божественным самоубийством, т.е. полным уничтожением божественной и сверхъестественной реальности. Он подмигнул и улыбнулся в свойственной ему угрюмой манере: "Я уже говорил тебе, что не продумал до конца эти вещи. Нет, я думаю, кое-что осталось". Вечное существо или вечная идея добра, которой не касается зло и опустошение исторического становления? Имеем ли мы дело с этим поздним потомком платоновской идеи блага?» [5; S. 70].

Интерес таких выдающихся ученых и общественных деятелей, как Э. Майр и С. Доннелли, к творчеству Ганса Йонаса доказывает актуальность его идей в области философии живого и этики ответственности.

\section{ЛИТЕРАТУРА}

1. Колчинский Э.И. Эрнст Майер - архитектор, пропагандист и адвокат синтетической теории эволюции // Создатели современного эволюционного синтеза. - СПб.: Нестор-История, 2012. - С. 440-441.

2. Пугачева Н.П. Человек, жизнь и природа в философии Ганса Йонаса: монография. - Пенза: РИО ПГСХА, 2013. - 184 с.

3. Скворцов А.К. Лидер эволюционной биологии. К 100-летию Эрнста Майра // Природа. - 2004. - № 9. - С. 69-70.

4. Donnelley S. Bioethical Troubles: Animal Individuals and Human Organisms // The Hastings Center report. - 1995. - P. 21-29.

5. Donnelly S. Hans Jonas und Ernst Mayr: Über organisches Leben und menschliche Verantwortung // Mensch. Gott. Welt. Philosophie des Lebens, Religionsphilosophie und Methaphysik im Werk von Hans Jonas. - Freiburg, Berlin, Wien: Rombach, 2008. - S. 41-71.

6. Donnelley S. Speculative Philosophy, the Troubled Middle and Ethics of Animal Experimentation // The Hastings Center report. - 1989. - P. 15-21.

7. Jonas H. Das Prinzip Leben. - Frankfurt a. M.: Insel, 2011. - $408 \mathrm{~s}$.

8. Mensch. Gott. Welt. Philosophie des Lebens, Religionsphilosophie und Methaphysik im Werk von Hans Jonas. - Freiburg, Berlin, Wien: Rombach, 2008. - 476 s.

(c) Пугачева Наталья Петровна (kozlova_natalya@list.ru) 